\title{
FERACOL ${ }^{\circledR}$ PASTE BAIT FOR POSSUM CONTROL - A CAGE TRIAL
}

\author{
D.R. MORGAN and A.T. RHODES
}

\section{Landcare Research, P.O. Box 69, Lincoln 8152, New Zealand}

\begin{abstract}
Consumption and efficacy of $\mathrm{FeraCol}^{\circledR}$ paste (containing $0.4 \%$ cholecalciferol) were assessed in a cage trial by presenting 20 captive possums with $18 \mathrm{~g}$ of paste, a quantity predicted to be suitable for 'lowhazard' use when presented in small paper bags attached to trees. All possums ate some paste and $90 \%$ were killed. The two survivors had both eaten moderate amounts of paste suggesting that it may be necessary to reassess the concentration of cholecalciferol once reliable data are gained from actual field use. Consumption of FeraCol ${ }^{\circledR}$ paste induced a 'stop-feed' effect which, together with its durable nature, should permit use of the product in a relatively cost-effective manner with low environmental risk.
\end{abstract}

Keywords: possums, Trichosurus vulpecula, vertebrate pest control, cholecalciferol.

\section{INTRODUCTION}

$\mathrm{FeraCol}^{\circledR}$ is a new type of possum paste bait manufactured by Feral Control (Auckland). It comprises a peanut base and the active ingredient, cholecalciferol (i.e. vitamin $\mathrm{D}_{3}$ ), at a nominal concentration of $0.4 \%$ weight:weight. In the possum (Trichosurus vulpecula), toxic doses of cholecalciferol mobilise stores of calcium from bones to the bloodstream and produce hypercalcaemia and calcification of the blood vessels, primarily in the cardiovascular system, kidneys, stomach and lungs. Mineralisation and blockage of blood vessels then lead to heart failure and death, generally in 4 to 7 days (Jolly et al. 1993). The possum is particularly susceptible to cholecalciferol poisoning $\left(\mathrm{LD}_{50}=16.8 \mathrm{mg} / \mathrm{kg}\right)$ compared with, for example, dogs $(80$ $\mathrm{mg} / \mathrm{kg}$ ) or ducks (2000 mg/kg) (Haydock and Eason 1997). The susceptibility of the possum to cholecalciferol provides an opportunity to develop baiting strategies in which limited quantities of bait are presented with relatively low risk to non-target animals.

Consequently, it is envisaged that a major use pattern will be the attachment to trees of biodegradable paper bags containing $18 \mathrm{~g}$ paste, a quantity estimated to be lethal to most possums. In addition to reducing the likelihood of birds and grounddwelling animals encountering and feeding on baits, this delivery method would grant the paste bait an extended field life, thus increasing the chances of possums encountering and eating a theoretically lethal quantity of bait, even when sparsely distributed. This is usually the case during the 'maintenance' phase, i.e. following initial 'knockdown', of ongoing control.

Another characteristic of cholecalciferol poisoning in possums is the loss of appetite that occurs after about 24 hours following ingestion of the toxic bait (Jolly et al. 1995). This ensures that, after feeding on the bait, possums are unlikely to eat further bait on subsequent nights. By placing the paste in paper bags, baits can be retained for use elsewhere, thus minimising waste and reducing operational costs.

We therefore conducted a trial with caged possums to examine the key parameters, efficacy and effect on appetite, underlying the effective use of FeraCol@ in the baiting strategy described above. 


\section{METHODS}

Twenty possums, captured in North Canterbury, were housed at the Landcare Research Animal Facility, Lincoln. The possums were maintained in individual cages on a diet of fresh fruit, vegetables and supplementary dietary pellets. Fresh drinking water was always available. The possums were acclimatised to captivity for at least 4 weeks before the study started.

Feracol $^{\circledR}$ (Feral Control, Auckland) contained, nominally, $0.4 \%$ weight:weight cholecalciferol. Each of the 20 possums was presented, at normal feeding time (i.e. 3:00 p.m.), with $17.9-18.4 \mathrm{~g} \mathrm{FeraCol}^{\circledR}$ paste on a glass dish. At the same time, about half the normal daily ration of fruit and vegetable was presented. About $1 \mathrm{~h}$ after possums had eaten the bait, the other half of the daily ration was offered. This procedure was followed to simulate as much as practical: (i) the expected manner in which paste baits may be encountered in the wild (i.e. with restricted amounts of alternative foods available nearby) and (ii) the likely combination of paste bait with other foods over the possum's main feeding period (i.e. the first hour of feeding). The weight of remaining bait was recorded after $24 \mathrm{~h}$. Two samples of $18 \mathrm{~g}$ of bait in dishes, not available to possums, were also prepared and these were reweighed to monitor changes in the weight of bait. The time until death for each possum was estimated to the nearest half day.

The daily consumption of dietary feed pellets for each possum was recorded from 2 days before bait was presented (to establish baseline appetite level) until 22 days after bait was offered. Changes in consumption were used to monitor the effect of the FeraCol $^{\circledR}$ on appetite.

The study was conducted with the approval of the Landcare Research Animal Ethics Committee (approval no. 99/5/1).

\section{RESULTS}

Possums ate between 8.7 and $18.4 \mathrm{~g}$ of $\mathrm{FeraCol}^{\circledR}$ paste (Table 1) resulting in mortality of $90 \%$. The two possums that survived had eaten 15.9 and $11.9 \mathrm{~g}$ paste.

There was no significant difference in the mean quantity eaten by males $(15.4 \mathrm{~g})$ and females (15.8 g) (non-paired $\mathrm{t}_{18}=0.3$, two-tailed $\mathrm{P}>0.05$ ). Most possums died between 3 and 10 days after eating FeraCol ${ }^{\circledR}$ paste (Fig. 1). One possum died 14.5 days

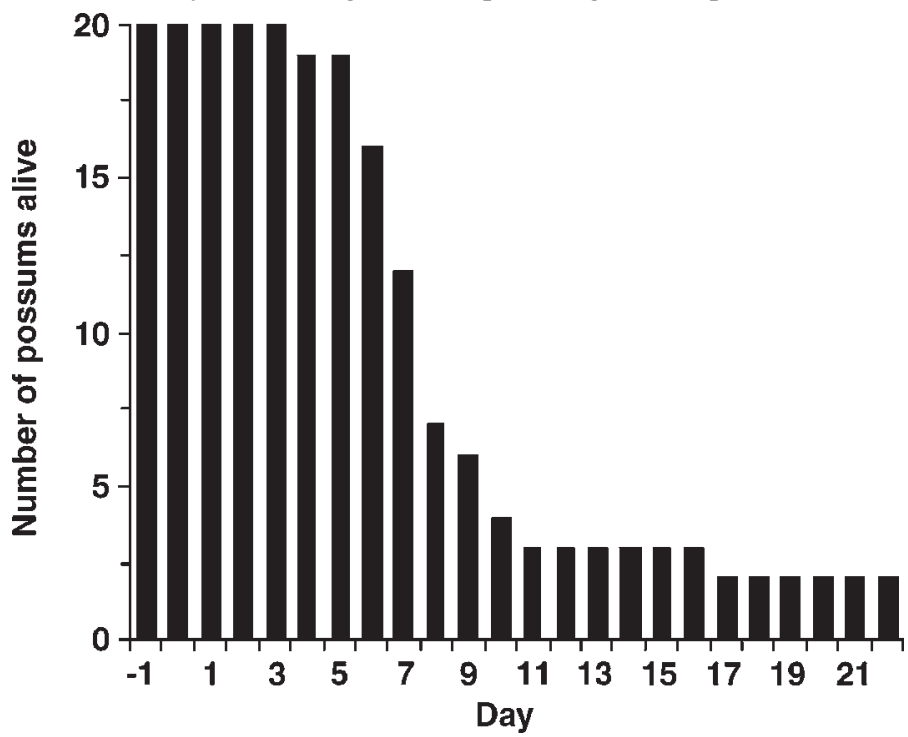

FIGURE 1: Pattern of mortality in possums after eating FeraCol $^{\circledR}$ paste. 
after eating paste. There was no significant difference in the time until death between males ( 6.9 days) and females (6.2 days) (non-paired $\mathrm{t}_{16}=0.4$, two-tailed $\mathrm{P}>0.05$ ). No possums lost more than $25 \%$ body weight before death. Note that loss of more than $25 \%$ body weight is used as an Animal Ethics Committee-approved study 'end point' at which animals are euthanased in the interests of animal welfare.

The daily consumption of dietary feed pellets (Fig. 2) illustrates the 'stop-feed' effect normally associated with cholecalciferol baits. On the night after baits were presented, food consumption declined by around $50 \%$ and by night 3 very little food was eaten. Although only two possums survived, it appears that normal appetite resumed about 3 weeks after baits were eaten.

TABLE 1: Consumption of FeraCol ${ }^{\circledR}$ and time until death for 20 settled, captive possums, each presented with $18 \mathrm{~g}$ of $\mathrm{FeraCol}^{\circledR}$. The weight of three $18 \mathrm{~g}$ 'control' samples of $\mathrm{FeraCol}^{\circledR}$ remained unchanged, avoiding the need for correction of data due to dehydration

\begin{tabular}{|c|c|c|c|c|c|}
\hline $\begin{array}{l}\text { Possum } \\
\text { No. }\end{array}$ & Sex & $\begin{array}{l}\text { Body } \\
\text { weight } \\
\text { (kg) }\end{array}$ & $\begin{array}{l}\text { Weight of } \\
\text { FeraCol }^{\circledR} \\
\text { eaten }\end{array}$ & $\begin{array}{l}\text { Dose } \\
\text { ingested } \\
(\mathrm{mg} / \mathrm{kg})\end{array}$ & $\begin{array}{l}\text { Days until } \\
\text { death (hours } \\
\text { until death) }\end{array}$ \\
\hline 1 & M & 3.03 & 10.3 & 13.6 & $5.5(132)$ \\
\hline 2 & M & 2.92 & 12.9 & 17.7 & $5.5(132)$ \\
\hline 3 & M & 2.46 & 17.2 & 28.0 & $4.5(108)$ \\
\hline 4 & M & 2.73 & 16.8 & 24.6 & $8.5(204)$ \\
\hline 5 & M & 3.04 & 17.5 & 23.0 & $7.5(180)$ \\
\hline 6 & M & 2.47 & 15.9 & 25.8 & Survived \\
\hline 7 & M & 3.16 & 18.4 & 23.3 & $9.5(228)$ \\
\hline 8 & M & 2.41 & 8.7 & 14.4 & $8.5(204)$ \\
\hline 9 & M & 2.72 & 18.0 & 26.5 & $4.5(108)$ \\
\hline 10 & M & 2.60 & 18.0 & 27.7 & $6.5(156)$ \\
\hline 11 & $\mathrm{~F}$ & 2.12 & 13.9 & 26.2 & $5.5(132)$ \\
\hline 12 & $\mathrm{~F}$ & 2.29 & 8.7 & 15.2 & $4.5(108)$ \\
\hline 13 & $\mathrm{~F}$ & 2.09 & 17.9 & 34.3 & $5.5(132)$ \\
\hline 14 & $\mathrm{~F}$ & 3.02 & 18.0 & 23.8 & $14.5(348)$ \\
\hline 15 & $\mathrm{~F}$ & 2.15 & 17.7 & 32.9 & $6.5(156)$ \\
\hline 16 & $\mathrm{~F}$ & 2.68 & 17.6 & 26.3 & $5.5(132)$ \\
\hline 17 & $\mathrm{~F}$ & 2.38 & 11.9 & 20.0 & Survived \\
\hline 18 & $\mathrm{~F}$ & 2.57 & 16.2 & 25.2 & $4.5(108)$ \\
\hline 19 & $\mathrm{~F}$ & 2.03 & 17.9 & 35.3 & $4.5(108)$ \\
\hline 20 & $\mathrm{~F}$ & 2.13 & 17.9 & 33.6 & $3.0 \quad(72)$ \\
\hline Mean & & 2.55 & 15.6 & 24.9 & $6.4(153.6)$ \\
\hline $\mathrm{SD}^{1}$ & & 0.34 & 3.2 & 6.4 & $2.9 \quad(69.6)$ \\
\hline $95 \% \mathrm{CI}^{2}$ & & 0.16 & 1.5 & 2.8 & $1.3 \quad(31.2)$ \\
\hline
\end{tabular}

${ }^{1}$ Standard deviation. $\quad{ }^{2}$ Confidence interval.

\section{DISCUSSION}

These findings indicate that $\mathrm{FeraCol}^{\circledR}$ paste should be readily accepted by possums and will kill ca $90 \%$ that encounter a single $18 \mathrm{~g}$ bait. Although we did not present paste in paper bags in this trial (to avoid imprecision in measuring the amounts consumed) earlier trials with baits in thin plastic bags indicated that possums will readily consume baits presented in this manner (Morgan et al. 1993).

The survival of two possums that ingested moderate doses of cholecalciferol confirms the wide range of susceptibility in possums to this toxicant noted by others (Jolly et al. 1995). If field-usage of FeraCol® does not result in kills regularly exceeding $90 \%$, we would recommend increasing the concentration of cholecalciferol in the bait for further cage-efficacy trials. 


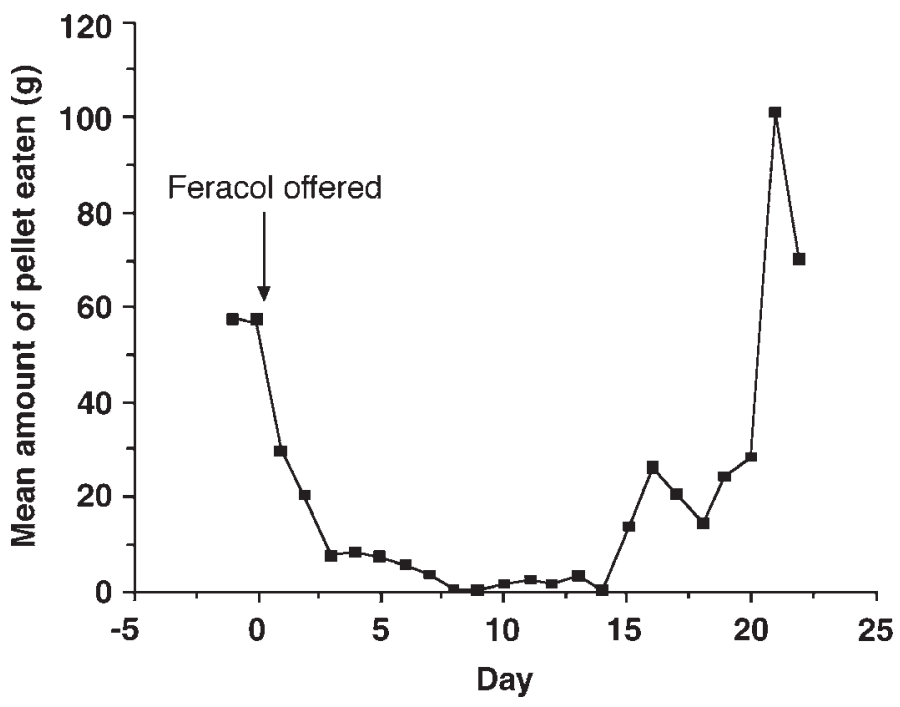

FIGURE 2: Mean daily consumption of dietary feed pellets after possums ate FeraCol ${ }^{\circledR}$ paste.

The 'stop-feed' effect induced by cholecalciferol is a highly desirable characteristic of this toxicant that avoids both costly 'over-consumption' of bait and the resulting highly toxic possum carcasses. By comparison, possums in the field consumed, on average, approximately $400 \mathrm{~g}$ of bait containing brodifacoum (a slow-acting anticoagulant poison) in a 4-week period before death (Henderson et al. 1997). This is equivalent to an average of four $\mathrm{LD}_{95}$ doses (Eason et al. 1994). Because brodifacoum persists in the tissues for extended periods, carcasses of such animals may present a secondary poisoning hazard to scavenging feral pigs and a possible tertiary poisoning hazard to pig hunters and dogs eating contaminated wild pig meat (Eason et al. 1999). Such hazards from use of FeraCol® are highly unlikely. An ongoing study of bait field life suggests that the oily texture of the bait and the use of paper bags for bait delivery are likely to confer a field life of at least $2-3$ months (D. Morgan, unpubl. data).

While the study was not designed to assess the humaneness of FeraCol@ in killing possums, no animals exceeded the $25 \%$ loss in body weight used as a study end-point for avoiding excessive suffering, despite the loss of appetite. Therefore on the basis of reduced appetite and body weight, and in the absence of any overt symptoms of distress during toxicosis, FeraCol@ would appear to be a humane option for possum control. Further behavioural and physiological studies are, however, needed to confirm this preliminary assessment.

Together, our data on efficacy, effect on diet and weight loss, and the durable nature of the paste in the field suggest that FeraCol ${ }^{\circledR}$ could be used very costeffectively, humanely and with low environmental risk by attachment of single bags to trees at a rate of perhaps 10-20/ha, depending on possum density.

\section{REFERENCES}

Eason, C.T., Henderson, R., Thomas, M.D. and Frampton, C.M., 1994. The advantages and disadvantages of sodium monofluoroacetate and alternative toxins for possum control. In: Proceedings of the Science Workshop on 1080. A.A. Seawright and C.T.Eason (Eds); The Royal Society of New Zealand, Misc. Ser. 28: 159-165. 
Eason, C.T., Milne, L., Potts, M., Morriss, G., Wright, G.R.G. and Sutherland, O., 1999. Secondary and tertiary poisoning risks associated with brodifacoum.N.Z.J. Ecol. 23: 219-224.

Haydock, N. and Eason, C.T., 1997. Vertebrate Pest Control Manual. Toxins and Poisons. Department of Conservation, Wellington. 88p.

Henderson, R.J., Morriss, G.A. and Morgan, D.R., 1997. The use of different types of toxic bait for sustained control of possums. Proc. 50th N.Z. Plant Prot. Conf:: 382390.

Jolly, S.E., Eason, C.T. and Frampton, C., 1993. Serum calcium levels in response to cholecalciferol and calcium carbonate in the Australian brushtail possum. Pest. Biochem. Physiol. 47: 159-164.

Jolly, S.E., Henderson, R.J., Frampton, C. and Eason, C.T., 1995. Cholecalciferol toxicity and its enhancement by calcium carbonate in the common brushtail possum. Wild. Res. 22: 579-583.

Morgan, D.R., Warburton, B., Henderson, R.J. and Eason C.T., 1993. New types of possum baits suitable for farmer use. Landcare Research contract report LC93945/ 06 (unpublished). 16p. 